\title{
Antiaging Activity of Gel Preparation Containing Three Varieties of Passion Fruit Peel Ethanolic Extract
}

\author{
Nazliniwaty Nazliniwaty ${ }^{1}$, Fathur Rahman Harun ${ }^{2}$, Effendy De Lux Putra ${ }^{2}$, Nerdy Nerdy ${ }^{3 *}$ \\ ${ }^{1}$ Department of Pharmaceutical Technology, Faculty of Pharmacy, University of Sumatera Utara, Padang Bulan, Medan \\ Baru, Medan, Sumatera Utara 20155, Indonesia; ${ }^{2}$ Department of Pharmaceutical Chemistry, Faculty of Pharmacy, University \\ of Sumatera Utara, Padang Bulan, Medan Baru, Medan, Sumatera Utara 20155, Indonesia; ${ }^{3}$ Department of Pharmacy, \\ Faculty of Pharmacy, Institut Kesehatan Deli Husada Deli Tua, Deli Tua Timur, Deli Tua, Deli Serdang, Sumatera Utara, \\ 20355, Indonesia
}

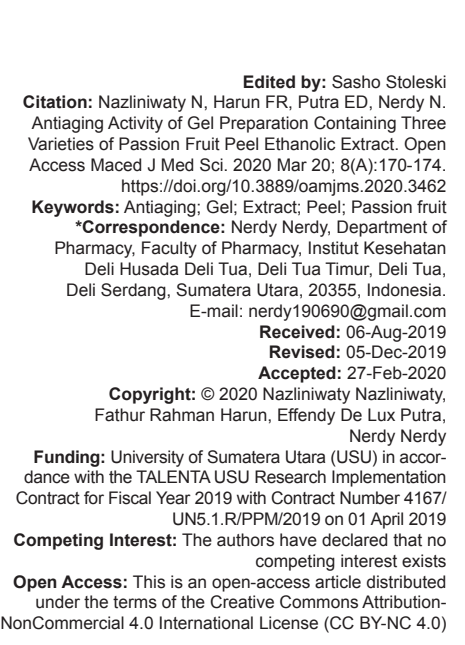

\section{Abstract}

BACKGROUND: Antiaging cosmetics are cosmetics that can prevent or correct the signs of premature aging Passion fruit (Passiflora sp.) peel is an agricultural waste contains polyphenol compounds and flavonoids which are a source of natural antioxidants to prevent premature aging. The passion fruit peel extract formulated into gel preparations which can increase the economic value of the passion fruit peel waste.

OBJECTIVE: The objective of the study was to test the antiaging activity of gel preparations containing ethanolic extracts of purple, red, and yellow passion fruit on experimental animal skins with several parameters (wrinkle, melanin, pore, moisture, and elasticity).

METHODS: Gel was made by adding passion fruit peel extract with several concentrations $(0.05 \%, 0.10 \%, 0.15 \%$, $0.20 \%$, and $0.25 \%$ ) in gel base. The blank used is a gel base without extracts. Measurement of wrinkle, black pigment (melanin), pore size, moisture content, and elasticity was performed using a skin analyzer. The use of ge is done 2 times a day for 28 days.

RESULTS: Gel with purple, red, and yellow passion fruit peel extract can be formulated into gel preparations. The higher concentration of passion fruit peel extract shows a higher antiaging activity. Gel preparations with purple, red and yellow passion fruit peel extract, respectively, show the recovery of wrinkle $16.16 \%, 8.73 \%$, and $6.49 \%$; recovery of melanin $20.11 \%, 10.75 \%$, and $8.06 \%$; recovery of pore $18.78 \%, 10.15 \%$, and $7.69 \%$; recovery of moisture $32.74 \%$, $17.70 \%$, and $13.04 \%$; and recovery of elasticity $30.08 \%, 16.13 \%$, and $12.30 \%$.

CONCLUSIONS: The highest antiaging activity was given by gel preparations containing purple passion fruit peel extract and the lowest antiaging activity was given by gel preparations with yellow passion fruit peel extracts.

\section{Introduction}

The aging process is an inevitable physiological process that will be experienced by every human being. This process is irreversible which covers all organs of the body including the skin. Ironically, this aging process is seen as a scary thing by most people, even though this process will continue along with increasing age [1]. Passion fruit is one of the most abundant types of plants in Indonesia. Utilization of passion fruit is still limited to the passion fruit flesh. The processing of passion fruit peel is still very limited and is often as agricultural waste. Passion fruit peel contains flavonoid (the secondary metabolites) which has pharmacological activity as anticancer and antioxidant [2].

Passion fruit has much variety that is seen from differences in peel color. Variety of passion fruit that grows in Indonesia is purple passion fruit, red passion fruit, and yellow passion fruit. Differences in fruit variety have an impact on differences in phytochemical content contained in the fruit, which results in differences in biological activity [3]. The use of antioxidants is one effort that is often done to prevent the aging process of skin aging. One natural antioxidant is passion fruit peel. Utilization of antioxidant effects on preparations intended for skin treatment is very well formulated in topical dosage forms [4].

Thegel is a form of pharmaceutical preparation, defined as a semisolid form that can be easily mixed with water. Gel preparations are widely used and are often used because they are comfortable (not sticky) and easy to clean (can be mixed with water [5]. Based on the described background, an antiaging activity test of purple, red, and yellow passion fruit peel extracts will be carried out in gel formulation. The purpose of this study was to determine differences in the antiaging activity of ethanol extracts of passion fruit peel in different variety (purple, red, and yellow passion fruit). 


\section{Materials and Methods}

\section{Materials}

The materials used in this research were passion fruit peel, ethanol pro-analysis grade (Merck, Germany), hydroxypropyl methylcellulose Pharma Grade (Sigma, Germany), methyl parahydroxybenzoate Pharma Grade (Ueno, India), propyl parahydroxybenzoate Pharma Grade (Ueno, India), propylene glycol Pharma Grade (Wilmar, Singapore), distilled water pro-analysis grade (Merck, Germany), and marketed antiaging gel Alavie $^{\circledR}$ (Avalon, Britain). The experimental animal used in this research was white rats with Wistar strain.

\section{Tools}

The tools used in this research were analytical balance (Sartorius, Germany), balance (Acis, China), cutter (Kenko, Indonesia), drying cabinet (Memmert, Germany), skin analyzer type APM 100 (Aram Huvis, Korea), mortar and pestle (Fischer, Germany), blender (Philips, Indonesia), rotary evaporator (Buchi, Germany), and other laboratory glassware (Iwaki, Indonesia).

\section{Preparation of extract}

Preparation of extract is a modification of the method of Ahmad et al., 2018. Different varieties of passion fruit peel were collected $10 \mathrm{~kg}$ for each passion fruit peel, washed thoroughly with running water, cut to a small piece, dried in a drying cabinet at $40^{\circ} \mathrm{C}-60^{\circ} \mathrm{C}$ until dry, powdered using a blender, stored in a plastic container which is tightly closed and protected from heat and sunlight, weighed the simplicia powder, and obtained the total dry simplicia weight. The simplicia powder was weighed at $500 \mathrm{~g}$, put into a closed vessel, added $3.75 \mathrm{~L}$ ( 75 parts solvent of a total of $5 \mathrm{~L}$ ) of $70 \%$ ethanol as the solvent, stored at room temperature for 5 days protected from light while frequently stirring, filtered out the extraction mixture, and squeezed. The pulp is put into a closed vessel, added $1.25 \mathrm{~L}$ (25 parts solvent from a total of $5 \mathrm{~L}$ ) of $70 \%$ ethanol solvent, left at room temperature for 5 days protected from light while frequently stirring, filtered out the extraction mixture, and squeezed [6]. The first and second extraction results (macerate) are combined, evaporated with a rotary evaporator at a temperature of approximately $40^{\circ} \mathrm{C}$, a concentrated extract is obtained and calculated the yield of the extract.

\section{Preparation of gel}

The formulation of gel bases is a modification of the method of Kurniawansyah et al., 2018. Formula of gel base: Hydroxy propylmethylcellulose $2.75 \mathrm{~g}$; methyl parahydroxybenzoate $0.15 \mathrm{~g}$; propyl parahydroxybenzoate $0.05 \mathrm{~g}$; propylene glycol $20 \mathrm{~g}$; and distilled water until $100 \mathrm{~g}$.

Preparation of a gel base: Hydroxy propylmethylcellulose is first developed in water, an amount of 20 times its weight at $70^{\circ} \mathrm{C}$, left for about $30 \mathrm{~min}$. Methyl parahydroxybenzoate and propyl parahydroxybenzoate have been dissolved with propylene glycol, crushed with hydroxypropyl methylcellulose which has been expanded, added the remaining water needed.

\section{Formulation of gel}

Gel extract formulation: Extracts have been weighed according to the formula, put into mortars, added to the base gel little by a little while crushed until homogeneous [7].

\section{Antiaging activity test}

Antiaging activity testing is a modification of the Sumaiyah and Leisyah methods, 2019. The experimental animals (white rats with Wistar Strain) consisted of 18 groups with each group consisting of six experimental animals with ethical clearance from Health Research Ethics Committees, Department of Biology, Faculty of Mathematics and Natural Sciences, University of Sumatera Utara. Experimental animals were acclimatized for 1 week with a cycle of $12 \mathrm{~h}$ of light and $12 \mathrm{~h}$ of darkness, given enough food, and free access to water ad libitum. Experimental animals have shaved the back hair in $3 \mathrm{~cm} \times 3 \mathrm{~cm}$, measured at the initial of the skin condition with various skin parameters (wrinkle, melanin, pore, humidity, and elasticity) using a skin analyzer.

Group I: Treatment of formula A; Group II: Treatment of formula B; Group III: Treatment of formula C; Group IV: Treatment of formula D; Group V: Treatment of formula E; Group VI: Treatment of formula F; Group VII: Treatment of formula G; Group VIII: Treatment of formula $\mathrm{H}$; Group IX: Treatment of formula I; Group X: Treatment of formula J; Group XI: Treatment of formula K; Group XII: Treatment of formula L; Group XIII: Treatment of formula M; Group XIV: Treatment of formula N; Group XV: Treatment of formula O; Group XVI: Treatment of formula $\mathrm{P}$

\begin{tabular}{|c|c|c|c|c|c|c|c|c|c|c|c|c|c|c|c|c|c|}
\hline \multirow[t]{2}{*}{ Number } & \multirow[t]{2}{*}{ Materials } & \multicolumn{16}{|c|}{ Formula } \\
\hline & & $\bar{A}$ & B & C & $\mathrm{D}$ & $E$ & $\mathrm{~F}$ & G & $\mathrm{H}$ & $\mathrm{I}$ & $\mathrm{J}$ & $\mathrm{K}$ & $\mathrm{L}$ & $\mathrm{M}$ & $\mathrm{N}$ & 0 & $\mathrm{P}$ \\
\hline$\overline{1 .}$ & Purple passion fruit peel & 0.05 & 0.10 & 0.15 & 0.20 & 0.25 & - & - & - & - & - & - & - & - & - & - & - \\
\hline 2. & Red passion fruit peel & - & - & - & - & - & 0.05 & 0.10 & 0.15 & 0.20 & 0.25 & - & - & - & - & - & - \\
\hline 3. & Red passion fruit peel & - & - & - & - & - & - & - & - & - & - & 0.05 & 0.10 & 0.15 & 0.20 & 0.25 & - \\
\hline 4. & Gel base & 99.95 & 99.90 & 99.85 & 99.80 & 99.75 & 99.95 & 99.90 & 99.85 & 99.80 & 99.75 & 99.95 & 99.90 & 99.85 & 99.80 & 99.75 & 100 \\
\hline$\Sigma$ & Total & 100 & 100 & 100 & 100 & 100 & 100 & 100 & 100 & 100 & 100 & 100 & 100 & 100 & 100 & 100 & 100 \\
\hline
\end{tabular}


(control blank); Group XVII: Alavie ${ }^{\circledR}$ (positive control) market preparedness treatment; Group XVIII: Without treatment (negative control).

Experimental animals were applied the gel to the skin (which has been shaved the back hair) with frequency twice daily (at 06.00 and 18.00), exposed to sunlight between 06.00 and 18.00 , observed the changes in skin conditions (wrinkle, melanin, pore, humidity, and elasticity) measured every 7 days for 28 days, and analyzed the results of research data using the Statistical Package for the Social Sciences program using one-way analysis of variance/one-way ANOVA [8]

\section{Results and Discussion}

The results of antiaging activity testing with various parameters wrinkle, melanin, pore, moisture, and elasticity before treatment and after treatment for 1 week, 2 weeks, 3 weeks, and 4 weeks are shown in Figures 1-5.

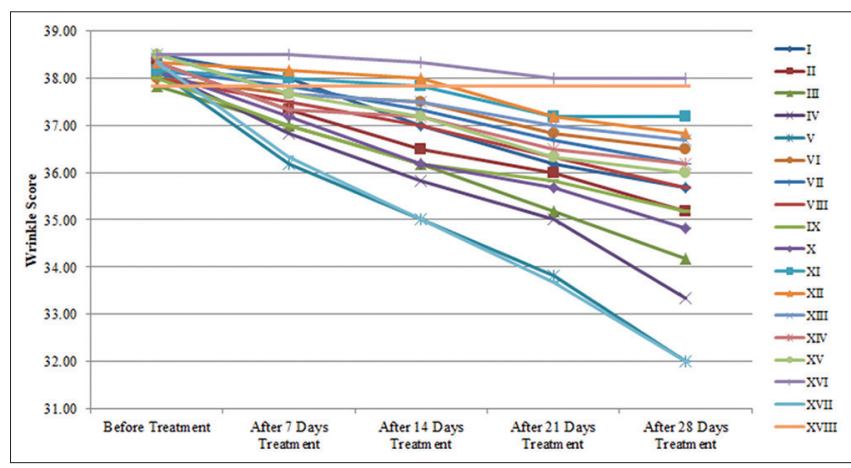

Figure 1: Wrinkle profile before and after various treatments

Flavonoids as antioxidants can inhibit increased levels of matrix metalloproteinase -1 (MMP-1) [9]. MMP-1 is a key mediator that degrades collagen in photoaged skin. Barriers to the MMP-1 are one way to prevent skin damage from exposure to ultraviolet light.

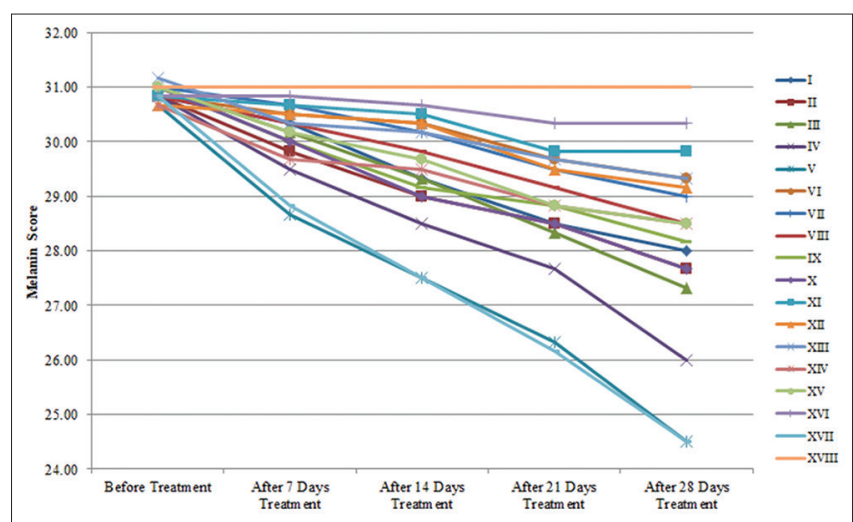

Figure 2: Melanin profile before and after various treatments

Flavonoids can also play a role in inhibiting and preventing skin damage by free radicals caused by exposure to ultraviolet light on the skin, by binding to oxygen singlet and inhibiting lipid peroxidation so

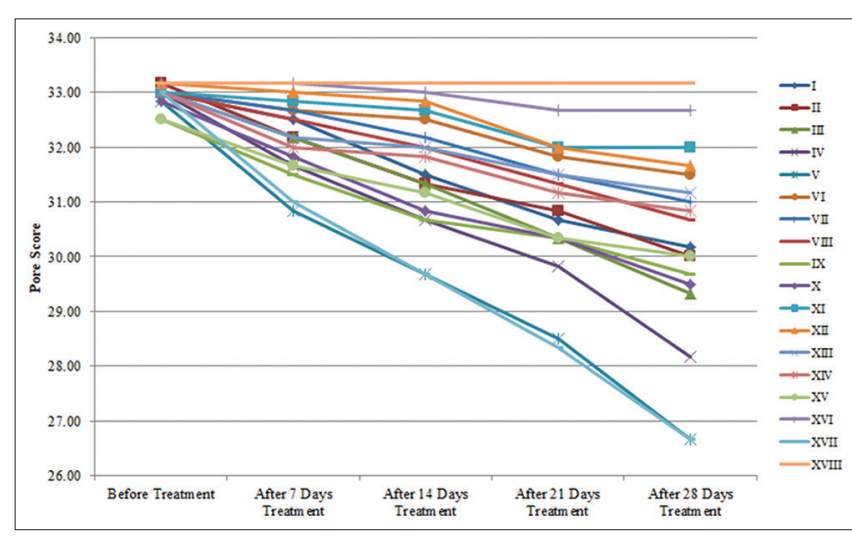

Figure 3: Pore profile before and after various treatments

that the synthesis of MMP-1 will be reduced and the collagen degradation process is inhibited so that the skin is protected from premature aging due to ultraviolet light exposure [10].

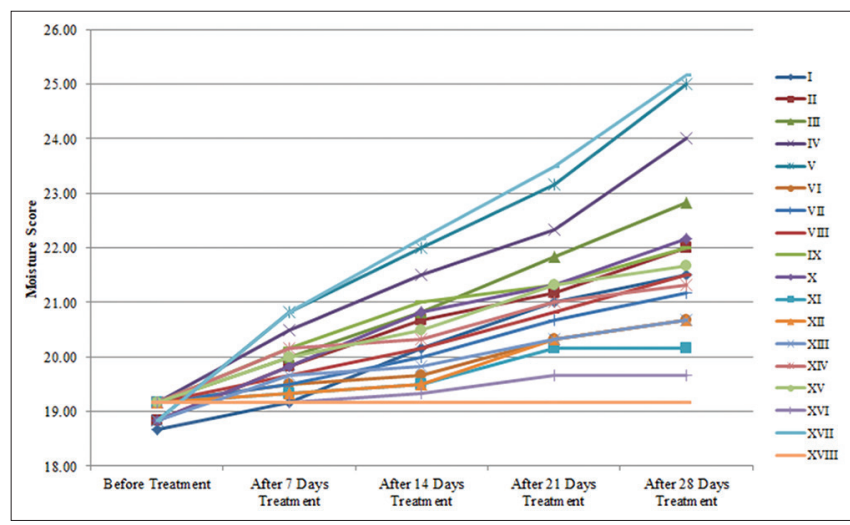

Figure 4: Moisture profile before and after various treatments

Hyperpigmentation can occur on aging skin and skin that has not aged due to various causes [11] In general, these black spots appear on parts of the body that is often exposed to sunlight [12], [13]. The longer the skin is exposed to sunlight, causing the formation of melanin, the skin becomes more active and causes blemishes on the skin [14]. Flavonoids have a competitive effect on the enzyme tyrosinase inhibitor [15] which inhibits tyrosine to Dopa and Dopakuinon, so it can inhibit the increase in the amount of melanin in melanocyte cells and also has antioxidant effects that can function to protect the skin from free radicals [16].

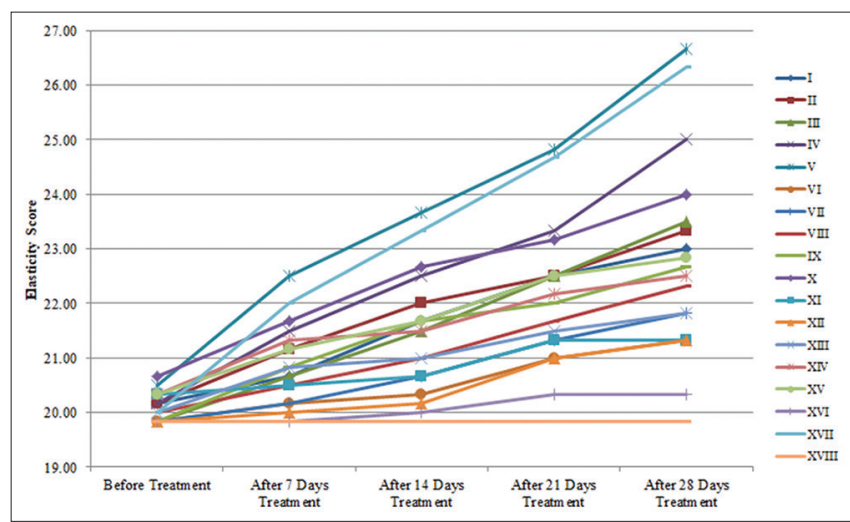

Figure 5: Elasticity profile before and after various treatments 
Pore in the skin is a small hole in the skin where hair follicles grow which keeps human skin hydrated by producing sebum. One of the causes of skin problems is a blockage in the pore so that dirt and dead skin cells accumulate resulting in skin problems such as rough and dull [17]. Flavonoids as antioxidants can inhibit lipid peroxidation reactions and are good reducing compounds. Flavonoids act as a good antidote for hydroxyl radicals and superoxide so that the lipid membrane is protected. This can help reduce pore size and improve skin texture [18], [19].

Factors that greatly affect water levels in the epidermis and dermis are nutrition and the environment [1]. The skin must be able to maintain the water content to maintain its function as healthy skin. The water content in healthy skin is $60 \%$ so that the skin remains elastic, bright, and functioning properly. For physiological functions, the skin needs fat and water. The layer of fat on the surface of the skin and the ingredients in the stratum corneum that are hygroscopic can absorb water and is in a functional relationship called the natural moisturizing factor. The ability of the stratum corneum to bind water is very important for the flexibility and flexibility of the skin. The ability of the skin to absorb (absorption) is strongly influenced by metabolism, moisture, and skin thickness [20].

The skin can be a mirror of the state of body condition. Unhealthy people have skin that tends to wrinkle, less bright, porous, dry, and not elastic, which can be caused by malnutrition and nutrition. Meanwhile, to ward off bad effects due to exposure to sunlight, dust, friction, and weather changes, the skin needs balanced nutrition such as protein and fat. Besides, the skin needs Vitamin $C$ which is useful as collagen. The body needs Vitamin A, Vitamin C, and Vitamin $\mathrm{E}$ as antioxidants (protecting the skin from external influences). Unsaturated fatty acids also play a role in maintaining skin elasticity [21].

After testing for 4 weeks, the calculation of recovery of the skin is carried out. The results of the calculation of skin recovery with parameters wrinkle, melanin, pore, moisture, and elasticity are shown in Table 1.

Table 1: Skin recovery after 4 weeks of treatment

\begin{tabular}{|c|c|c|c|c|c|}
\hline \multirow[t]{3}{*}{ Group } & \multicolumn{5}{|c|}{ Average results } \\
\hline & \multicolumn{5}{|c|}{ Recovery (\%) } \\
\hline & Wrinkle & Melanin & Pore & Moisture & Elasticity \\
\hline $\mathrm{I}$ & 7.36 & 9.19 & 8.59 & 15.18 & 14.05 \\
\hline II & 8.26 & 10.27 & 9.55 & 16.81 & 15.70 \\
\hline III & 9.69 & 11.83 & 11.11 & 19.13 & 18.49 \\
\hline IV & 12.66 & 15.68 & 14.65 & 25.22 & 23.97 \\
\hline V & 16.16 & 20.11 & 18.78 & 32.74 & 30.08 \\
\hline VI & 3.95 & 4.86 & 4.55 & 7.83 & 7.56 \\
\hline VII & 5.24 & 6.45 & 6.06 & 10.43 & 10.08 \\
\hline VIII & 6.14 & 7.57 & 7.07 & 12.17 & 11.67 \\
\hline IX & 7.46 & 9.14 & 8.72 & 14.78 & 14.29 \\
\hline$x$ & 8.73 & 10.75 & 10.15 & 17.70 & 16.13 \\
\hline XI & 2.62 & 3.24 & 3.03 & 5.22 & 4.92 \\
\hline XII & 3.91 & 4.89 & 4.52 & 7.83 & 7.56 \\
\hline XIII & 4.76 & 5.88 & 5.56 & 9.73 & 9.17 \\
\hline XIV & 5.65 & 7.07 & 6.57 & 11.30 & 10.66 \\
\hline$x V$ & 6.49 & 8.06 & 7.69 & 13.04 & 12.30 \\
\hline XVI & 1.30 & 1.62 & 1.51 & 2.61 & 2.52 \\
\hline XVII & 16.52 & 20.54 & 19.19 & 33.63 & 31.67 \\
\hline XVIII & 0.00 & 0.00 & 0.00 & 0.00 & 0.00 \\
\hline
\end{tabular}

From the results of the study, it can be seen that application of the purple, red, and yellow passion fruit peel extracts in gel preparation to the skin of provides antiaging by reducing the wrinkle, melanin, and pore, also increase the skin moisture and elasticity. Application with gel preparation containing $0.25 \%$ purple passion fruit peel extract (group V) to experimental animal skin provides the best antiaging activity compared to the other treatment and also provides a similar (not significantly different) antiaging activity to Group XVIII which applied the marketed antiaging gel to the experimental animal skin. The higher concentration of passion fruit peel extract in the gel preparation shows better antiaging activity.

The antiaging effect of gel preparations containing passion fruit peel extract shows the antiaging effects that depend on the extract concentration. Differences in antiaging effects that cause by a different variety of passion fruit peel occur due to differences in the type and amount of phytochemical compounds contained in passion fruit peel extract [3]. Skin aging can be caused by intrinsic and extrinsic factors. Intrinsic factors are factors within the body itself (age, genetic, racial, and hormonal) that cannot be avoided, called intrinsic aging. Skin aging can be caused by extrinsic factors (environment, disease, pressure, smoking, alcohol, and chemicals) that can be avoided, called extrinsic aging. Extrinsic aging will cause premature aging to the skin. Premature aging is aging that occurs faster than it should [22].

\section{Conclusions}

The highest antiaging activity was given by gel preparations containing purple passion fruit peel extract and the lowest antiaging activity was given by gel preparations with yellow passion fruit peel extracts. The higher concentration of passion fruit peel extract in gel preparations will result higher antiaging activity of the gel preparations.

\section{Acknowledgement}

The research was funded by the University of Sumatera Utara (USU) in accordance with the TALENTA USU Research Implementation Contract for Fiscal Year 2019 with Contract Number 4167/UN5.1.R/PPM/2019 on 01 April 2019.

\section{References}

1. Zhang S, Duan E. Fighting against skin aging: The way from bench to bedside. Cell Transplant. 2018;27(5):729-38. https:// 
doi.org/10.1177/0963689717725755

PMid:29692196

2. Wong YS, Sia CH, Khoo HE, Ang YK, Chang SK, Yim HS Influence of extraction conditions on antioxidant properties of passion fruit (Passiflora edulis) Peel. Acta Sci Pol Techno Aliment. 2014;13(3):257-65. https://doi.org/10.17306/j. afs.2014.3.4

PMid:24887941

3. Thokchom R, Mandal G. Production preference and importance of passion fruit (Passiflora edulis): A review. J Agric Eng Technol. 2017;4(1):27-30.

4. Vollmer DL, West VA, Lephart ED. Enhancing skin health: By oral administration of natural compounds and minerals with implications to the dermal microbiome. Int $\mathrm{J}$ Mol Sci. 2018;19(10):E3059. https://doi.org/10.3390/ijms19103059 PMid:30301271

5. Singh D, Sachan AK, Kumar S. Formulation and evaluation of topical gel delivery of lornoxicam. World J Pharm Pharm Sci. 2018;7(6):884-96.

6. Ahmad I, Mulia K, Yanuar A, Mun'im A. Metabolite profiling analysis of conventional and non-conventional extraction methods on secondary metabolite from Peperomia pellucida (L.) Kunth using UPLC-QToF-MS/MS system. J Young Pharm. 2018;10(2s):S40-4. https://doi.org/10.5530/jyp.2018.2s.8

7. Kurniawansyah IS, Sopyan I, Wardhana YW, Gunasekaran M Formulation and evaluation of chloramphenicol hydroge ophthalmic preparation. J Young Pharm. 2018;10(2):S73-8. https://doi.org/10.5530/jyp.2018.2s.14

8. Sumaiyah S, Leisyah BM. The effect of antioxidant of grapeseed oil as skin anti-aging in nanoemulsion and emulsion preparations. Rasayan J Chem. 2019;12(3):1185-94. https://doi. org/10.31788/rjc.2019.1235337

9. Kim HI, Jeong YU, Kim JH, Park YJ. 3, 5, 6, 7, 8, 3', 4'-Heptamethoxyflavone, a citrus flavonoid, inhibits collagenase activity and induces Type I procollagen synthesis in HDFn cells. Int J Mol Sci. 2018;19(2):E620. https://doi.org/10.3390/ ijms 19020620

PMid:29470423

10. Ginwala R, Bhavsar R, Chigbu DI, Jain P, Khan ZK. Potential role of flavonoids in treating chronic inflammatory diseases with a special focus on the anti-inflammatory activity of apigenin. Antioxidants (Basel). 2019;8(2):E35. https://doi.org/10.3390/ antiox8020035 PMid:30764536

11. Stout $R$, Birch-Machin M. Mitochondria's role in skin ageing. Biology (Basel). 2019;8(1):E29. https://doi.org/10.3390/ biology 8020029

PMid:31083540
12. Choi W, Yin L, Smuda C, Batzer J, Hearing VJ, Kolbe L. Molecular and histological characterization of age spots. Exp Dermatol. 2017;26(3):242-8. https://doi.org/10.1111/exd.13203 PMid:27621222

13. Bino SD, Duval C, Bernerd F. Clinical and biological characterization of skin pigmentation diversity and its consequences on UV impact. Int J Mol Sci. 2018;19(9):E2668. https://doi.org/10.3390/ijms19092668 PMid:30205563

14. Webb AR, Kazantzidis A, Kift RC, Farrar MD, Wilkinson J, Rhodes LE. Colour counts: Sunlight and skin type as drivers of Vitamin D deficiency at UK latitudes. Nutrients. 2018;10(4):E457. https://doi.org/10.3390/nu10040457

PMid:29642423

15. Zolghadri S, Bahrami A, Khan MT, Munoz-Munoz J, GarciaMolina F, Garcia-Canovas F, et al. A comprehensive review on tyrosinase inhibitors. J Enzyme Inhib Med Chem. 2019;34(1):279309. https://doi.org/10.1080/14756366.2018.1545767 PMid:30734608

16. Ifeanyi OE. A review on free radicals and antioxidants. Int J Curr Res Med Sci. 2018;4(2):123-33.

17. Rembiesa J, Ruzgas T, Engblom J, Holefors A. The impact of pollution on skin and proper efficacy testing for anti-pollution claims. Cosmetics. 2018;5(1):4-12. https://doi.org/10.3390/ cosmetics5010004

18. Campa M, Baron E. Anti-aging effects of select botanicals: Scientific evidence and current trends. Cosmetics. 2018;5(3):5468. https://doi.org/10.3390/cosmetics5030054

19. Petruk G, Giudice RD, Rigano MM, Monti DM. Antioxidants from plants protect against skin photoaging. Oxid Med Cell Longev. 2018;2018:1454936. https://doi.org/10.1155/2018/1454936 PMid:30174780

20. Lu F, Wang C. Zhao R, Du L, Fang Z, Guo X, Zhao Z. Review of stratum corneum impedance measurement in non-invasive penetration application. Biosensors (Basel). 2018;8(2):E31. https://doi.org/10.3390/bios8020031 PMid:29587456

21. Schagen SK, Zampeli VA, Makrantonaki E, Zouboulis CC Discovering the link between nutrition and skin aging. Dermatoendocrinol. 2012;4(3):298-307. https://doi.org/10.4161/ derm.22876 PMid:23467449

22. Addor FA. Beyond photoaging: Additional factors involved in the process of skin aging. Clin Cosmet Investig Dermatol. 2018;11:437-43. https://doi.org/10.2147/ccid.s177448 PMid:30288075 